\title{
Monoterpene Flavonoid from Aerial Parts of Satureja khuzistanica
}

\author{
Mansooreh Davoodi $^{\odot}$, Abdolhossein Rustaiyan ${ }^{\circledR * 1}$ and Samad N. Ebrahimi ${ }^{\odot * 2}$ \\ ${ }^{1}$ Department of Chemistry, Science \& Research Branch, Islamic Azad University, Tehran, Iran. \\ ${ }^{2}$ Department of Phytochemistry, Medicinal Plants and Drugs Research Institute, Shahid Beheshti \\ University, G. C., Evin, Tehran, Iran
}

(Received June 14, 2017; Revised September 13, 2017; Accepted September 13, 2017)

\begin{abstract}
Fractionation of methanolic extract of Satureja khuzistanica Jamzad by Sephadex LH-20 and reverse phase chromatography led to the isolation and purification of a new monoterpene flavonoid (1), as well as six previously detected flavonoid derivatives (2-6). The structure assignment has been performed by using 1D, 2D $\mathrm{NMR}$, and high-resolution MS spectrometry. In addition, electronic circular dichroism (ECD) spectroscopy was used to reveal the absolute configuration of 1 .
\end{abstract}

Keywords: Lamiaceae; monoterpene flavonoid; structure elucidation; ECD. C 2018 ACG Publications. All rights reserved.

\section{Plant Source}

The plant material of Satureja khuzistanica Jamzad was provided from the field of Khoraman Pharmaceutical Company, Khorramabad, Iran (2012), and was recognized by Dr. Javad Hadian. In addition, a voucher specimen (MPH-1582) was deposited at the Herbarium of the Department of Biology, Medicinal Plants, and Drugs Research Institute affiliated with Shahid Beheshti University (Tehran, Iran).

\section{Previous Studies}

The Satureja genus belongs to Lamiaceae family and contains over 30 species. The plants are mostly aromatic herbs distributed in the Mediterranean area, Middle East, North Africa, and Central Asia. Some of these species such as Satureja montana, S. atropatana and S. hortensis have been used as flavoring agents, herbal teas, and food additives [1,2]. In central part of Iran, the local people have been used the aerial part of $S$. khuzistanica for medical practitioners, analgesic, antibacterial, and antifungal purposes [3-5]. The essential oil composition of S. khuzistanica and its biological activities have been studied comprehensively [2-4]. Nevertheless, there are a few reports on the phytochemical profile of nonvolatile constituents. A review of the literature revealed that rosmarinic acid, flavonoids, and triterpenoids are main compounds of S. khuzistanica aerial parts [6-8].

\footnotetext{
* Corresponding author: E- Mail: s_ebrahimi@sbu.ac.ir (Samad N. Ebrahimi); Phone +98-21 29904052. 


\section{Present Study}

Dried leaf material of Satureja khuzistanica $(800 \mathrm{~g})$ was ground, and then extracted through successive percolation with $\mathrm{CH}_{2} \mathrm{Cl}_{2}, \mathrm{EtOAc}$, and $\mathrm{MeOH}(3 \times 5 \mathrm{~L}$ each). After evaporation to dryness under reduced pressure, $60 \mathrm{~g}$ of $\mathrm{MeOH}$ extract obtained. Then the extract was dissolved in distilled water (1L) passed through a Diaion HP-20 resin column $(9 \times 45 \mathrm{~cm})$. The column rinsed with distilled water $(3 \times$ $1.5 \mathrm{~L})$. The enriched phenolic fraction obtained by rinsing the column with $\mathrm{MeOH}(3 \times 1 \mathrm{~L})$ and evaporated under vacuum to give $15.0 \mathrm{~g}$ gummy material. The obtained enriched polyphenols dissolved in $100 \mathrm{ml} \mathrm{MeOH}$ and after filtration subjected to gel chromatography on Sephadex LH-20 column (55 × $880 \mathrm{~mm}$ ). In the next stage, the column eluted with $\mathrm{MeOH}$ with a flow rate of $2.5 \mathrm{ml} / \mathrm{min}$. 180 fractions were collected and monitored by TLC chromatography (EtOAc: MeOH, 8:2, detection at 254 and 360 $\mathrm{nm}$ ), and were pooled into twelve major fractions (Fr 1-12). Fraction 5 (400 $\mathrm{mg}$ ) was exposed to flash chromatography using a silica cartridge (Puriflash C18-HP $15 \mu \mathrm{m}, 40 \mathrm{~g}$ ), Interchim, Montluçon, France) to provide 13 subfractions (F5-1to F5-13). Subfraction F5-11 (5.0mg) was separated by a semipreparative RP-HPLC by using a gradient of $\mathrm{H}_{2} \mathrm{O} / \mathrm{MeCN}$ (both with a $0.1 \%$ formic acid content) (80:20 to $50: 50$ over $26 \mathrm{~min}$ until it reached $100 \% \mathrm{MeCN}$ in $10 \mathrm{~min}$ ) at a flow rate of $4.0 \mathrm{~mL} / \mathrm{min}$ to afford compound $2\left(0.8 \mathrm{mg}, t_{R} 19.0 \mathrm{~min}\right), \mathbf{3}\left(1.1 \mathrm{mg}, t_{R} 22.0 \mathrm{~min}\right), \mathbf{1}\left(0.3 \mathrm{mg}, t_{R} 25.0 \mathrm{~min}\right)$, and $4\left(0.3 \mathrm{mg}, t_{R} 27.0\right.$ $\mathrm{min})$. The reverse phase chromatography of subfraction F5-7 by a semi-preparative HPLC by the above method afforded compounds $5\left(0.9 \mathrm{mg}, t_{R} 29.0 \mathrm{~min}\right)$, and $6\left(0.8 \mathrm{mg}, t_{R} 32.0 \mathrm{~min}\right)$.

Compound 1, yellowish powder; ECD $\left(\mathrm{c}=0.8 \mathrm{mM}, \mathrm{MeOH}, 25^{\circ} \mathrm{C}\right): \lambda(\Delta \varepsilon)=224(+4897), 258(+1326)$, 296 (-3084), 332 (+1118). UV (MeOH):217(3.9), 278 (3.5), 335(3.6); HR-ESI-MS $m / z=451.1375$ [M$\mathrm{H}]^{-}$: (Calcd 451.1398 for $\left.\mathrm{C}_{25} \mathrm{H}_{24} \mathrm{O}_{8}\right)$. ${ }^{1} \mathrm{HNMR}$ (DMSO-d6, $\left.500.13 \mathrm{MHz}\right): \delta 1.13(6 \mathrm{H}, \mathrm{d}, \mathrm{J}=6.9 \mathrm{~Hz}, \mathrm{Me}-$ 10",Me- 9"), 2.04 (3H, s, Me-7"), 3.09 (1H, sep, J=6.9 Hz, H-8"), 4.99 (1H, d, J=11.0 Hz, H-2), 4.45 $(1 \mathrm{H}, \mathrm{d}, \mathrm{J}=11.0 \mathrm{~Hz}, \mathrm{H}-3), 5.81(1 \mathrm{H}$, brs, $\mathrm{H}-6), 5.85\left(1 \mathrm{H}\right.$, brs, H-8), $6.52\left(1 \mathrm{H}, \mathrm{d}, J=8.3 \mathrm{~Hz}, \mathrm{H}-5^{\prime}\right), 6.55$ $\left(1 \mathrm{H}, \mathrm{s}, \mathrm{H}-6^{\prime \prime}\right), 6.75\left(1 \mathrm{H}, \mathrm{s}, \mathrm{H}-3^{\prime \prime}\right), 6.81\left(1 \mathrm{H}, \mathrm{dd}, \mathrm{J}=8.3,1.9 \mathrm{~Hz}, \mathrm{H}-6^{\prime}\right), 7.09\left(1 \mathrm{H}, \mathrm{d}, \mathrm{J}=1.9 \mathrm{~Hz}, \mathrm{H}-2^{\prime}\right) ;{ }^{13} \mathrm{C}$ NMR (125.1 MHz, DMSO-d6): $\delta 15.8$ (C-7"), 23.3 (C-10" and C-9"), 26.4 (C-8"), 71.9 (C-3), 82.9 (C2), 95.9 (C-6), 96.6 (C-8), 151.0(C-4'), 100.5 (C-10), 112.9 (C-3"), 147.3 (C-3'), 119.2 (C-6'), 116.5 (C$\left.2^{\prime}\right), 120.6\left(\mathrm{C}-6^{\prime \prime}\right), 123.6\left(\mathrm{C}-1^{\prime \prime}\right), 132.2\left(\mathrm{C}-1^{\prime}\right), 138.5\left(\mathrm{C}-4^{\prime \prime}\right), 145.3\left(\mathrm{C}-5^{\prime \prime}\right), 116.5\left(\mathrm{C}-5^{\prime}\right), 151.9\left(\mathrm{C}-2^{\prime \prime}\right)$, 159.1 (C-9), 166.7 (C-7), 197.1 (C-4).

The phytochemical profiling of methanolic extract of $S$. khuzistanica carried out by partitioning using diaion HP-20 resin, Sephadex LH-20, and preparative and semi-preparative reverse phase chromatography. A new monoterpene flavonoid plus five known flavonoid derivatives (Figure 1) were identified through the isolation and purification of selected fractions. The structure of these compounds was depicted by means of 1D and 2D NMR spectroscopy and the comparison of those published data. The identified compounds were: keshonin (2) [12], saturejin (3'-(2,5-dihydroxy-p-cymene) 5,7,4'trihydroxyflavone) (3) [6], ponciretin (4) [13], 5,6-dihydroxy-3',4',7-trimethoxyflavone (5) [14], 5,6dihydroxy-4',7-dimethoxyflavone (6)[15], and acacetin (7) [6]. Compounds 2-5 were the first isolated from S. khuzistanica. 


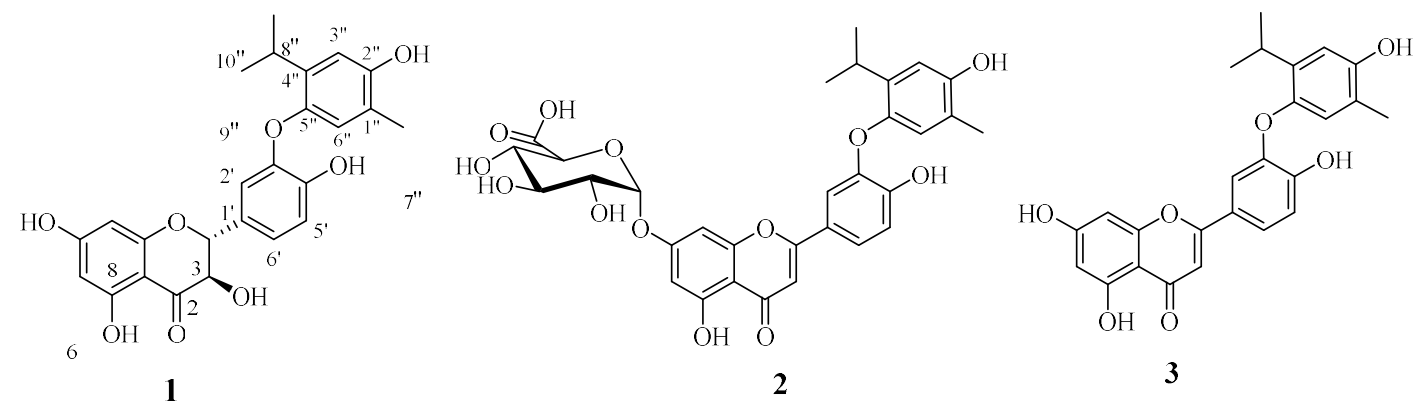<smiles>COc1ccc([C@H]2CC(=O)c3c(O)cc(O)cc3O2)cc1</smiles>

4<smiles>COc1ccc(-c2cc(=O)c3c(O)c(O)c(OC)cc3o2)cc1</smiles>

6<smiles>COc1ccc(-c2cc(=O)c3c(O)cc(O)cc3o2)cc1</smiles>

7

Figure 1. Structures of isolated compounds from S. khuzistanica

Compound 1 was obtained as a yellow amorphous powder with a molecular formula of $\mathrm{C}_{25} \mathrm{H}_{24} \mathrm{O}_{8}$ from high-resolution TOF-MS (m/z $451.1375[\mathrm{M}-\mathrm{H}]-$ : calculated 451.1398). It showed absorbance in UV spectroscopy at 278 and $335 \mathrm{~nm}$, typical of flavonoids. In the 1H NMR spectrum, seven aromatic proton signals at $\delta \mathrm{H} 7.09\left(\mathrm{~d}, \mathrm{~J}=1.9 \mathrm{~Hz}, \mathrm{H}-2^{\prime}\right), \delta \mathrm{H} 6.81\left(\mathrm{dd}, \mathrm{J}=8.3,1.9 \mathrm{~Hz}, \mathrm{H}-6^{\prime}\right), \delta \mathrm{H} 6.75\left(\mathrm{~s}, \mathrm{H}-3^{\prime \prime}\right), \delta \mathrm{H}$ $6.55\left(\mathrm{~s}, \mathrm{H}-6^{\prime \prime}\right), \delta \mathrm{H} 6.52\left(\mathrm{~d}, \mathrm{~J}=8.3 \mathrm{~Hz}, \mathrm{H}-5^{\prime}\right), \delta \mathrm{H} 5.85(\mathrm{brs}, \mathrm{H}-8)$, and $\delta \mathrm{H}$ 5.81(brs, H-6), together with methine proton signals at $\delta \mathrm{H} 4.45(\mathrm{~d}, \mathrm{~J}=11 \mathrm{~Hz}, \mathrm{H}-3)$ and $\delta \mathrm{H} 4.99(\mathrm{~d}, \mathrm{~J}=11 \mathrm{~Hz}, \mathrm{H}-2)$ suggested flavone

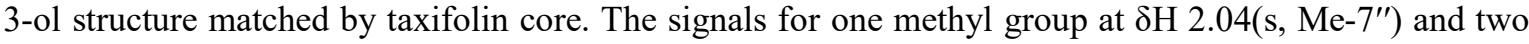
methyl groups at $\delta \mathrm{H} 1.13(\mathrm{~d}, \mathrm{~J}=6.9 \mathrm{~Hz}$, Me-9" and 10") that coupled with methyl group at $\delta \mathrm{H} 3.09$ (sep, $\mathrm{H}-8^{\prime \prime}$ ) showed the presence of p-cymene-2,5-diol moiety. The arrangement of the methyl group at 5" was confirmed by HMBC correlation from H-7" to C-1" and C-2". The cross peak in HMBC between H-8", Me-9" and Me-10" to C-4" confirmed the presence of thymoquinol moiety which is comparable to saturejin. The key cross-signal in NOESY spectrum between Me-9" and Me-10" to H-2' on ring B suggested that thymoquinol moiety was attached to position $3^{\prime}$ [12]. The analysis of various spectral data indicated that this compound should be structured as monoterpene-flavonoid (3'-(2,5-dihydroxy-pcymene),5,7,-trihydroxyflavol. Besides, the vicinal coupling constant between $\mathrm{H}-2 / \mathrm{H}-3 \quad(\mathrm{~J}=11 \mathrm{~Hz})$ corresponded with trans-orientation dihedral angel of about 170-180 degree. Therefore, two stereoisomer are possible $2 S, 3 S / 2 R 3 R$. The absolute configuration of position C-2 and C-3 deduced by comparison with those published data [16]. The experimental ECD spectrum of 1 displayed two positive Cotton effects (CE) at 332 and $215 \mathrm{~nm}$ and a negative CE at $296 \mathrm{~nm}$ (figure S13). A assessment of ECD spectrum showed the good agreement with $2 R, 3 R$ configuration comparing to $(+)$-taxifloin, with sequential positive and negative CEs at 330 and $295 \mathrm{~nm}$, respectively [16]. Therefore, compound 1 was a new natural product named as saturejenol (1).

\section{Acknowledgments}

The NMR spectra have been measured in Department of Pharmaceutical Biology, University of Basel, and we express our sincere thanks to Prof. M. Hamburger for his kind cooperation and Dr. J. Hadian for providing the plant material.

\section{Supporting Information}

Supporting Information accompanies this paper on http://www.acgpubs.org/RNP 


\section{ORCID}

Mansooreh Davoodi: 0000-0001-8789-4788

Abdolhossein Rustaiyan: 0000-0002-2293-132X

Samad N. Ebrahimi: $\underline{0000-0003-2167-8032}$

\section{References}

[1] A.R. Gohari, S. Saeidnia, M.R. Gohari, F. Moradi-Afrapoli, M. Malmir and A. Hadjiakhoondi (2009). Bioactive flavonoids from Satureja atropatana Bonge, Nat. Prod. Res. 23, 1609-1614.

[2] S. Saeidnia, A.R. Gohari, A. Manayi and M. Kourepaz-Mahmoodabadi (2015). Satureja: Ethnomedicine, Phytochemical Diversity and Pharmacological Activities, Springer.

[3] J. Hadian, M. Akramian, H. Heydari, H. Mumivand and B. Asghari (2012). Composition and in vitro antibacterial activity of essential oils from four Satureja species growing in Iran, Nat. Prod. Res. 26, 98-108.

[4] J. Hadian, M. Hossein Mirjalili, M. Reza Kanani, A. Salehnia and P. Ganjipoor (2011). Phytochemical and morphological characterization of Satureja khuzistanica Jamzad populations from Iran, Chem. Biod. 8, 902915.

[5] S. Momtaz and M. Abdollahi (2008). A systematic review of the biological activities of Satureja L. species, Pharmacologyonline 2, 34-54.

[6] M. Malmir, A.R. Gohari, S. Saeidnia and O. Silva (2015). A new bioactive monoterpene-flavonoid from Satureja khuzistanica, Fitoterapia 105, 107-112.

[7] F.M. Moghaddam, M.M. Farimani, S. Salahvarzi and G. Amin (2007). Chemical constituents of dichloromethane extract of cultivated Satureja khuzistanica, J. Evid. Based. Complemen. Altern. Med. 4, 9598.

[8] M. Tafazzoli, M. Ghiasi and M. Moridi (2008). Dynamic stereochemistry of erigeroside by measurement of ${ }^{1} \mathrm{H}-{ }^{1} \mathrm{H}$ and ${ }^{13} \mathrm{C}-{ }^{1} \mathrm{H}$ coupling constants, Spectrochim. Acta Mol. Biomol. Spectrosc. 70, 350-357.

[9] A. Bisio, A.M. Schito, S.N. Ebrahimi, M. Hamburger, G. Mele, G. Piatti, G. Romussi, F. Dal Piaz and N. De Tommasi (2015). Antibacterial compounds from Salvia adenophora Fernald (Lamiaceae), Phytochemistry 110, $120-132$.

[10] S.N. Ebrahimi, M.M. Farimani, F. Mirzania, M.A. Soltanipoor, M. De Mieri and M. Hamburger (2014). Manoyloxide sesterterpenoids from Salvia mirzayanii, J. Nat Prod. 77, 848-854.

[11] S.E. Moghadam, S.N. Ebrahimi, F. Gafner, J.B. Ochola, R.M. Marubu, W. Lwande, B.F. Haller and P. Salehi, M. Hamburger (2015), Metabolite profiling for caffeic acid oligomers in Satureja biflora, Ind. Crops Prod. 76, 892-899.

[12] K. Yamada, T. Murata, K. Kobayashi, T. Miyase and F. Yoshizaki (2010), A lipase inhibitor monoterpene and monoterpene glycosides from Monarda punctata, Phytochemistry 71, 1884-1891.

[13] D.H. Kim, B.G. Kim, Y. Lee, J.Y. Ryu, Y. Lim, H.G. Hur and J.H. Ahn (2005) Regiospecific methylation of naringenin to ponciretin by soybean O-methyltransferase expressed in Escherichia coli, J. Biotech. 119, 155162.

[14] T. Nagao, F. Abe, J. Kinjo and H. Okabe (2002), Antiproliferative constituents in plants 10. Flavones from the leaves of Lantana montevidensis Briq. and consideration of structure-activity relationship, Biol. Pharm. Bull. 25, 875-879.

[15] M.H. Farjam, A. Rustaiyan, E. Ezzatzadeh, A.R. Jassbi (2013). Labdane-type diterpene and two flavones from Salvia Sharifii Rech. f. and Esfan. and their biological activities, Iran J Pharm Res. 12, 395-399.

[16] G.-I. Nonaka, Y. Goto, J.-E. Kinjo, T. Nohara and I. Nishioka (1987). Tannins and related compounds. LII Studies on the constituents of the leaves of Thujopsis dolabrata Sieb. et Zucc, Chem. Pharm. Bull. 35, 11051108.

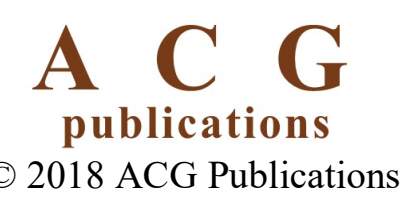

